\title{
Gender Differences in Academic Productivity and Advancement Among Dental School Faculty
}

\author{
Lisa Simon, DMD, ${ }^{1}$ Fiorella Candamo, DMD, ${ }^{2}$ Puhan He, DMD, ${ }^{3}$ Deepti Shroff Karhade, DMD, ${ }^{4}$ \\ Yasameen Pirooz, DMD, ${ }^{5}$ Mary Katherine Spinella, DMD, ${ }^{6}$ Mindy K. Truong, DMD, \\ Xuan $\mathrm{Wu}, \mathrm{DMD}^{8}$, and R. Bruce Donoff, MD, DMD ${ }^{9}$
}

\begin{abstract}
Background: An equal number of women and men are now graduating from dental school, but women dentists have lower income and are less likely to achieve positions of leadership, including within dental academia. Materials and Methods: Demographic information and academic rank were obtained for all faculty at the eight dental schools who received the most funding from the National Institute of Dental and Craniofacial Research in 2017. Years since dental school graduation, total number of PubMed-indexed citations, first- and last-author publications, and H-index were determined for each faculty member. Gender differences in productivity and advancement were evaluated.

Results: Of 702 faculty members, $36.5 \%$ were female; only $24.4 \%$ of full professors were women. Men had significantly higher numbers of publications (30.2 [95\% confidence interval [CI, 28.6-39.5] vs. 20.4 [95\% CI 16.3-24.6], $p=0.02$ ) and higher H-index (8.2 [95\% CI 7.1-9.1] vs. 4.7 [95\% CI 3.9-5.5], $p<0.0001)$. Women had graduated more recently than their male colleagues at all levels of academic advancement (overall 22.83 years [95\% CI 21.29-24.39] vs. 30.19 years [95\% CI 28.84-31.55], $p<0.0001$ ). When corrected for academic productivity and years since graduation, the association between gender and academic rank was not significant. Conclusions: Women are underrepresented at each academic rank except instructor; however, women may advance more quickly than their male counterparts. Increasing scholarship and mentorship opportunities for female faculty members may help improve gender equity in dental academia.
\end{abstract}

Keywords: academic careers, academic recruitment, faculty, dental, tenure, women faculty

\section{Introduction}

W HILE THE MAJORITY of practicing dentists are male, an equal number of men and women now graduate from dental school each year. ${ }^{1,2}$ This represents a rapid increase in gender parity in only a few decades; in the early 1980 s, women comprised less than five percent of all dental students. ${ }^{3}$

Despite this progress, large gender disparities in dental leadership persist across multiple arenas, including on editorial boards of dental journals, ${ }^{4}$ among department chairs and deans, ${ }^{5}$ and among presidents of major dental organiza- tions. ${ }^{6}$ Female dentists continue to earn a lower income than their male counterparts, and this income disparity in dentistry is higher than that present in medicine or law. ${ }^{7}$

Limited data suggest that women dentists may contribute disproportionately to reducing disparities in access for vulnerable populations; for example, young female dentists are more likely to practice in rural areas and work in the public sector. 8,9 Women dentists in the dental practicebased research network were more likely to emphasize prevention rather than treatment in their recommendations to patients. ${ }^{10}$

\footnotetext{
${ }^{1}$ Department of Oral Health Policy and Epidemiology, Harvard School of Dental Medicine, Department of Medical Education, Harvard Medical School, Boston, Massachusetts.

${ }^{2}$ Dental Corps, United States Navy, Washington, District of Columbia.

${ }^{3}$ Department of Oral and Maxillofacial Surgery, University of Pennsylvania School of Dental Medicine, Philadelphia, Pennsylvania

${ }^{4}$ Department of Pediatric Dentistry, University of North Carolina at Chapel Hill School of Dentistry, Chapel Hill, North Carolina.

${ }_{6}^{5}$ Department of Pediatric Dentistry, Columbia University School of Dental Medicine, New York, New York.

${ }^{6}$ Department of Oral and Maxillofacial Surgery, University of Texas Health Science Center at San Antonio, San Antonio, Texas.

${ }^{7}$ Department of Dentistry, La Maestra Community Health Clinic, San Diego, California.

${ }^{8}$ Office of Dental Education, Harvard School of Dental Medicine, Boston, Massachusetts.

${ }^{9}$ Office of Dental Education and Department of Oral and Maxillofacial Surgery, Harvard School of Dental Medicine, Boston, Massachusetts.
} 
Even during dental training, female students are more likely to report that they are treated differently than their male counterparts and report lower levels of confidence in their abilities. ${ }^{11}$ It has been suggested that women may be deterred from academia or more rigorous postgraduate training due to concerns about child rearing and family balance; however, women dentists themselves do not indicate this is the primary barrier to their full participation in the academic dental workforce. ${ }^{12}$

Key to addressing these inequalities and encouraging women to pursue careers in dental leadership, research, and service is to ensure sufficient female role models and mentorship for aspiring female dentists and dental leaders. Dental academia is the initial setting where dental students encounter the wide array of career possibilities open to them; yet women continue to make up a minority of dental school faculty. ${ }^{5}$

Studies from other medical disciplines have consistently shown that women have lower academic productivity than their male counterparts, and that they are less likely to achieve promotion to higher levels of academic rank. ${ }^{13-16}$ However, it is unknown whether these patterns persist in academic dentistry. The purpose of this exploratory study was to evaluate differences in academic productivity and rank among male and female faculty members at highly funded U.S. dental schools.

\section{Materials and Methods}

\section{Data collection}

This pilot study received an exemption from the Human Subjects Research Board (IRB18-0756). The eight institutions that received the most funding from the National Institute of Dental and Craniofacial Research (NIDCR) in financial year 2017 were selected for inclusion in the study. ${ }^{17}$ These schools were selected to exceed a sample size of 587, to ensure a $99 \%$ confidence level based on an estimated total population of 5061 full-time faculty at U.S. dental schools. ${ }^{18}$ One of these, the Forsyth Institute, is an affiliate of the Harvard School of Dental Medicine and all of its faculty have an appointment through Harvard, and so, this was considered one of the eight institutions. All full-time faculty were considered eligible for inclusion. If a listing of all full-time faculty was not available on the web, an administrator was contacted at the institution with a request for this information. Name, degrees, department, and academic rank were retrieved from publicly accessible university websites for all faculty. Gender was determined (in order of preference) from pronoun use within a publicly available biography, photo on the faculty members' profile page at their home institution, or by gender as listed on other websites (i.e., Healthgrades). Dental school, year of dental school graduation, specialty, and year of specialty graduation were obtained from university websites or by Internet search if not available. Due to heterogeneity of titles at different institutions, all faculty members with a title of less than assistant professor were listed as instructor.

The total number of PubMed-indexed publications for each faculty was obtained from institutional websites that included faculty publications indexed on PubMed, or via PubMed search using the individual's first and last names. For individuals with common names and/or a high index of suspicion for duplicate publications (e.g., publication names that indicated a subject substantially outside the expertise of the faculty member, or publications by an author substantially before the individual's graduation date), an advanced PubMed search was conducted, including the faculty members' name and their current institution. The number of first- and last-author publications were also assessed. $\mathrm{H}$-index was determined using an advanced search on Web of Science, including the faculty member's name and current institution. All searches were conducted between April 30, 2018, and May 20, 2018.

\section{Data analysis}

Descriptive statistics were calculated. Years since dental school graduation were available for more individuals than years since specialty graduation, so this was selected as the measure of career length. Academic rank was considered the primary variable. Because continuous variables were not normally distributed, Wilcoxon rank-sum tests were used to evaluate gender differences in number of publications and years since dental school graduation between men and women at each academic rank. As a secondary outcome, a logistic regression correcting for time since graduation with professor as the referent was conducted to evaluate odds ratios (ORs) for women to become full professors. $p$ Values $<0.05$ were considered significant. All analyses were conducted using Stata version 15.0.

\section{Results}

A total of 702 faculty members were included in the study. Of these, $446(63.5 \%)$ were men and $256(36.5 \%)$ were women. Gender was identified from a photograph for 428 individuals $(61.0 \%)$, by pronoun use in 142 individuals $(20.2 \%)$, by name for 76 individuals $(10.8 \%)$, and with listed gender for $56(8.0 \%)$. Five hundred eighty faculty members (79.9\%) were dentists, possessing a DMD, DDS, or BDS degree. Table 1 displays the names of the eight schools selected for inclusion and the proportion of men and women at each institution.

Women were most disproportionately represented at the level of assistant professor and professor $(39.8 \%$ and $24.4 \%$, respectively, $p<0.0001)$. Table 2 displays differences by gender in academic rank, PubMed publications, first and last authorship, and years since dental school graduation.

Men had a significantly greater number of total publications indexed on PubMed and a number of last-author publications (34.0 [95\% confidence interval, CI 28.6-39.5] vs. 20.4 [95\% CI 16.3-24.6], $p=0.02$ ). When stratified by academic rank, these differences were no longer significant. There were no significantly greater number of first-author publications among men and women faculty $(7.0$ [95\% CI 5.8-8.1] vs. 4.6 [95\% CI 3.7-5.5], $p=0.25)$. Men had a significantly higher $\mathrm{H}$-index than women faculty $(8.2[95 \% \mathrm{CI}$ 7.1-9.1] vs. 4.7 [95\% CI 3.9-5.5], $p<0.0001)$. When stratified by academic rank, the difference in $\mathrm{H}$-index was only significant at the level of full professor (11.4 [95\% CI 9.7$13.1]$ vs. 7.3 [95\% CI 5.2-9.4], $p=0.02$ ).

At all levels of academic rank, women had graduated significantly more recently than their male colleagues. On average, women academics had graduated 22.8 years previously (95\% CI 21.3-24.4), while men had graduated 30.2 years previously (95\% CI 28.9-31.6, $p<0.0001)$. The disparity in years since graduation was most dramatic at the instructor level (14.2 years for women [95\% CI 11.0-17.4]; 22.1 years for men [95\% CI 18.4-25.8], $p=0.0041)$. 
Table 1. Proportion of Female Faculty by Dental School in Order of National Institute of Dental and Craniofacial Research Funding

\begin{tabular}{lcrl}
\hline Dental school & Public/private status & Number of female faculty (\%) & Total faculty \\
\hline Total & & $256(36.5 \%)$ & 702 \\
University of Michigan & Public & $41(36.3 \%)$ & 113 \\
University of Alabama at Birmingham & Public & $20(34.5 \%)$ & 58 \\
University of California, San Francisco & Public & $33(44.0 \%)$ & 75 \\
University of Pittsburgh & Public & $52(32.5 \%)$ & 160 \\
Forsyth/Harvard School of Dental Medicine & Private & $43(48.3 \%)$ & 89 \\
University of Florida & Public & $22(35.5 \%)$ & 62 \\
University of Pennsylvania & Private & $23(31.5 \%)$ & 73 \\
University of California, Los Angeles & Public & $22(30.6 \%)$ & 72 \\
\hline
\end{tabular}

The average number of degrees at each level of academic advancement was $1.6,1.7,2.0$, and 1.9, respectively. There was no significant difference in number of degrees among men and women faculty at any level of academic rank or in total.

In a logistic regression model with full professor as the referent, men were 2.34 times more likely to be a full professor (OR 2.34 [95\% CI 1.66-3.32], $p<0.0001$ ); however, when corrected for years since graduation and number of PubMed citations, men were not significantly more likely to attain the rank of professor (OR 1.42 [95\% CI 0.90-2.23], $p=0.129)$. These odds ratios are displayed in Table 3 .

\section{Discussion}

In this preliminary exploratory study, we found that women were underrepresented in the academic dental workforce at eight dental schools, making up a proportion of the workforce similar to that reported at the national level. ${ }^{19} \mathrm{We}$ also found that women dental academics are less likely to be promoted to higher levels of academic rank, which can be explained by time since dental school graduation and their overall lower academic productivity as measured by PubMed-indexed citations and H-index. This lower academic productivity is consistent with findings from multiple medical specialties but, to our knowledge, has never been examined in dental academia. ${ }^{13-16}$

Gender disparities in academia could occur because women do not enter academia or because they choose to leave it or fail to advance. ${ }^{20}$ In our study, women represented more than half of entry-level (i.e., instructor rank) faculty; thus, it appears that women dentists are not dissuaded from entering academia but face other barriers in achieving advancement. This is consistent with the fact that women dental residents express higher rates of interest in academic careers than male residents. ${ }^{21}$ A survey of women dental faculty similarly revealed that the vast majority aspire to leadership in dental education and to utilize their talents at new levels. ${ }^{22}$

Table 2. Differences in Rank, Productivity, and Years Since Graduation by Gender

\begin{tabular}{|c|c|c|c|c|}
\hline & Overall $(95 \%$ CI $)$ & $\operatorname{Men}(95 \%$ CI $)$ & Women $(95 \%$ CI) & p Value \\
\hline Academic $\operatorname{rank}(N=701)^{\mathrm{a}}$ & & & & $<0.0001 *$ \\
\hline Instructor & 91 & $41(45.1 \%)$ & $50(54.9 \%)$ & \\
\hline Assistant Professor & 221 & $133(60.2 \%)$ & $88(39.8 \%)$ & \\
\hline Associate Professor & 147 & $79(53.7 \%)$ & $68(46.3 \%)$ & \\
\hline Professor & 242 & $183(75.6 \%)$ & $59(24.4 \%)$ & \\
\hline \multicolumn{5}{|l|}{ Mean publications $(N=657)^{\mathrm{b}}$} \\
\hline All PubMed publications & $28.5(24.8-32.2)$ & $34.0(28.6-39.5)$ & $20.4(16.3-24.6)$ & $0.02 *$ \\
\hline First author & $6.0(5.2-6.8)$ & $7.0(5.8-8.1)$ & $4.6(3.7-5.5)$ & 0.25 \\
\hline Last author & $9.6(7.8-11.4)$ & $12.1(9.3-14.9)$ & $5.8(4.2-7.4)$ & $0.0005 *$ \\
\hline H-index & $6.8(6.1-7.5)$ & $8.2(7.1-92)$ & $4.7(3.9-5.5)$ & $<0.0001 *$ \\
\hline \multicolumn{5}{|c|}{ Mean years since graduation $(N=549)^{\mathrm{b}}$} \\
\hline Total & $27.8(26.8-28.9)$ & $30.2(28.8-31.6)$ & $22.8(21.3-24.4)$ & $<0.0001^{*}$ \\
\hline Instructor & $19.2(16.5-21.9)$ & $22.1(18.4-25.8)$ & $14.2(11.0-17.4)$ & $0.0041 *$ \\
\hline Assistant Professor & $23.0(21.2-24.9)$ & $24.8(22.3-27.3)$ & $18.7(16.2-21.2)$ & $0.006^{*}$ \\
\hline Associate Professor & $29.2(27.1-31.3)$ & $31.8(28.8-34.8)$ & $25.5(23.0-28.1)$ & $0.008 *$ \\
\hline Professor & $34.6(33.2-36.0)$ & $35.6(33.9-37.4)$ & $29.1(29.1-33.4)$ & $0.003 *$ \\
\hline \multicolumn{5}{|c|}{ Mean number of degrees $(N=715)^{\mathrm{b}}$} \\
\hline Total & 1.80 & 1.8 & 1.8 & 0.88 \\
\hline Instructor & $1.6(1.4-1.7)$ & $1.5(1.3-1.7)$ & $1.6(1.4-1.8)$ & 0.40 \\
\hline Assistant Professor & $1.7(1.6-1.8)$ & $1.6(1.5-1.8)$ & $1.7(1.6-1.9)$ & 0.21 \\
\hline Associate Professor & $2.0(1.8-2.1)$ & $1.9(1.8-2.1)$ & $2.0(1.8-2.2)$ & 0.64 \\
\hline Professor & $1.9(1.8-2.0)$ & $2.0(1.9-2.1)$ & $1.8(1.6-2.1)$ & 0.13 \\
\hline
\end{tabular}

${ }_{p}^{\mathrm{a}} p$ Value determined using $\chi^{2}$ test.

$\mathrm{b}_{p}$ Values determined using Wilcoxon rank-sum test.

*Denotes significant $p$-value.

CI, confidence interval. 
Table 3. Odds Ratios of Promotion to Full Professor in Multivariable Logistic Regression

\begin{tabular}{|c|c|c|}
\hline Variable & $\begin{array}{c}\text { Odds ratio }[95 \% \\
\text { CI] }\end{array}$ & p Value \\
\hline Male gender & $1.42[0.90-2.23]$ & 0.13 \\
\hline Years since graduation & $1.08[1.06-1.10]$ & $<0.001 *$ \\
\hline $\begin{array}{l}\text { Number of PubMed } \\
\text { citations }\end{array}$ & $1.02[1.01-1.02]$ & $<0.001 *$ \\
\hline
\end{tabular}

*Denotes significant $p$-value.

Women physicians in academia receive a lower salary on average than men, a pattern present in academic dentistry at all academic ranks. ${ }^{23,24}$ Women in academic medicine are also impacted by bias in grant applications for federal research funding, ${ }^{25}$ unequal departmental resource allocation, ${ }^{26}$ and difficulty obtaining desired mentorship, limitations that are likely to be present in academic dentistry as well. ${ }^{27}$

Women may also be disproportionately impacted by personal factors related to societal demands, such as higher work burdens within the home. ${ }^{28}$ These persistent gender stereotypes also explain why women dental faculty perceive a less positive work environment than men, such as receiving less respect from students, different expectations from patients in clinical practice, and feeling less supported in achieving work-life balance. ${ }^{11,29,30}$ Unequal distributions of childcare and domestic responsibilities may help explain why women dentists outside of academia express preferences for more flexible practice settings; such flexibility may not be as readily available within traditional academic promotion pathways. ${ }^{12,31}$ Women seeking more flexible careers may also be more likely to pursue part-time, rather than full-time academic appointment, a conclusion that cannot be drawn from this study of only full-time dental academics. Institutional policies such as tenure clock "pauses" for parental leave, as well as equal parental leave policies for both male and female caregivers, may help reduce these disparities, especially as income disparities between men and women academics may be attributed to differences in taking time off. ${ }^{32}$

It is heartening that while women were underrepresented at all but the entry-level academic rank, women academics at each rank graduated more recently from training than their male counterparts. This pattern is different than what has been noted in other medical disciplines. ${ }^{13}$

It is interesting to note that while there was no significant difference in number of first-author publications between men and women, men had a greater number of publications overall and a greater number of last-author publications. The lack of statistical significance could be due to the overall male overrepresentation in our data set. However, it is also worth considering whether men may be more likely to be invited to collaborate on others' research (thus earning middle authorship) or be given the opportunity to mentor others' work (as a last author). Male faculty also had a higher H-index, indicating that men are more likely to have their work cited by others. Women's underrepresentation on the editorial boards of dental journals may compound these differences in publication and citation. ${ }^{4}$ Ensuring that women are included in collaborative research and are given positions of leadership on such research may increase the number of women-authored publications and provide additional op- portunities for academic advancement of women dental faculty.

It is important to consider the role of implicit bias in producing these disparities. Unconscious stereotypes and judgments may affect women's experience throughout their dental education, as well as when interviewing, applying for jobs and grant funding, and even when submitting journal articles to single-blinded peer-reviewed publications. Implicit bias training is being increasingly integrated into health profession education; its role within dental academia remains less explored. ${ }^{33}$

As a pilot, this study had a number of limitations. First, the use of photographs or third-party information to determine gender could be inaccurate for gender nonbinary or transgender faculty. Next, this representative sample consisted only of 8 of the 65 dental schools in the United States; as the schools selected were chosen for their higher levels of federally funded research, it is unknown whether these findings also apply to other dental schools. This study also did not take into account other options for professional advancement and promotion, including teaching responsibilities, clinical time, academic leadership (such as program director or dean titles), and amount of grant funding. Gender disparities in tenure track and nontenure track, as well as in clinical versus research promotion pathways, could not be evaluated as this information was not readily available for most faculty members. We are also unable to comment on gender disparities among part-time faculty, whose promotion pathways are generally different and are most often responsible for clinical teaching. As this was a cross-sectional study, we are unable to make conclusions about whether women's academic advancement and productivity are correlated over time, or whether their lower levels of productivity restrict promotion to higher levels of academic rank.

While PubMed citations and H-index are both commonly used measures of academic productivity, the use of these metrics may not have identified the full range of scholarly output for all faculty members. As women are more likely than men to change their last name after marriage, name changes may underestimate the number of publications for women faculty; the use of aggregated lists of faculty publications available on dental school's websites, which can be edited by faculty and their institutions, may have helped address this.

Ultimately, additional studies evaluating a broader scope of dental schools and using more rigorous bibliometric analyses are necessary to fully describe these gender disparities.

\section{Conclusions}

In this study of men and women faculty at the eight dental schools most highly funded by the NIDCR in 2017, men produced more citations on PubMed, had a greater number of last-author publications and a higher $\mathrm{H}$-index, and were more likely to obtain the rank of full professor. The difference in rank attainment was largely attributable to time since graduation and number of publications. Women were underrepresented at each academic rank except instructor; however, women appeared to obtain subsequent levels of advancement more quickly than their male counterparts.

Dental schools should continue to recruit and support women faculty and consider programming with an eye toward encouraging academic productivity and advancement 
for women in academic dentistry. Increased gender equity at all levels of academic rank can increase the quality and diversity of academic inquiry and increase accessibility of women mentors to dental students and trainees.

\section{Author Disclosure Statement}

No competing financial interests exist.

\section{References}

1. ADA Health Policy Institute. ADA health policy institute data center-supply of dentists, 2018. Available at: https:// ada.org/en/science-research/health-policy-institute/datacenter/supply-and-profile-of-dentists Accessed May 19, 2018.

2. Wanchek T, Cook BJ, Valachovic RW. Annual ADEA survey of dental school seniors: 2016 graduating class. J Dent Educ 2017;81:613-630.

3. Feldman CA, Lucas-Perry E, McAllister D. Attaining and sustaining leadership for U.S. women in dentistry. J Dent Educ 2015;79:S13-S17.

4. Ioannidou E, Rosania A. Under-representation of women on dental journal editorial boards. PLoS One 2015;10: e0116630.

5. Sinkford JC, Harrison S, Brunson WD, Valachovic RW Advancement of women in dental education: Expanding opportunities, enriching the pool. J Dent Educ 2011;75:707-711.

6. Whelton H, Wardman MJ. The landscape for women leaders in dental education, research, and practice. J Dent Educ 2015;79:S7-S12.

7. Nguyen Le TA, Lo Sasso AT, Vujicic M. Trends in the earnings gender gap among dentists, physicians, and lawyers. J Am Dent Assoc 2017;148:257-262.e2.

8. McFarland KK, Reinhardt JW, Yaseen M. Rural dentists of the future: Dental school enrollment strategies. J Dent Educ 2010;74:830-835.

9. Hopcraft MS, Milford E, Yapp K, et al. Factors associated with the recruitment and retention of dentists in the public sector. J Public Health Dent 2010;70:131-139.

10. Riley JL, Gordan VV, Rouisse KM, McClelland J, Gilbert GH, Dental Practice-Based Research Network Collaborative Group. Differences in male and female dentists' practice patterns regarding diagnosis and treatment of dental caries: Findings from the dental practice-based research network. J Am Dent Assoc 2011;142:429-440.

11. Tiwana KK, Kutcher MJ, Phillips C, Stein M, Oliver J. Gender issues in clinical dental education. J Dent Educ 2014;78:401-410.

12. Kolokythas A, Miloro M. Why do women choose to enter academic oral and maxillofacial surgery? J Oral Maxillofac Surg 2016;74:881-888.

13. McDermott M, Gelb DJ, Wilson K, et al. Sex differences in academic rank and publication rate at top-ranked US neurology programs. JAMA Neurol 2018;75:956-961.

14. Jena AB, Khullar D, Ho O, Olenski AR, Blumenthal DM. Sex differences in academic rank in US medical schools in 2014. JAMA 2015;314:1149.

15. Blumenthal DM, Olenski AR, Yeh RW, et al. Sex differences in faculty rank among academic cardiologists in the United States. Circulation 2017;135:506-517.

16. Holliday EB, Jagsi R, Wilson LD, et al. Gender differences in publication productivity, academic position, career duration, and funding among U.S. academic radiation oncology faculty. Acad Med 2014;89:767-773.
17. National Institute of Dental and Craniofacial Research. Rank listing of NIDCR grants to U.S. dental institutions, FY 2017|National Institute of Dental and Craniofacial Research, 2018. Available at: https://nidcr.nih.gov/grants-funding/ funding-to-schools-institutions/dental-schools/FY2017 Accessed May 13, 2018.

18. Wanchek T, Cook B, Slapar F, Valachovic R. Dental schools vacant budgeted faculty positions, academic year 2015-16. J Dent Educ 2017;81:1033-1043.

19. American Dental Education Association. ADEA snapshot of dental education, 2017-2018. Washington, DC: American Dental Education Association Press, 2017.

20. Wanchek T, Cook BJ, Anderson EL, Duranleau L, Valachovic RW. Dental school vacant budgeted faculty positions, academic years 2011-12 through 2013-14. J Dent Educ 2015;79:1230-1242.

21. Nazarova E, Martin-Peele M, Fifield J. U.S. dental specialty residents' expectations and anticipated benefits of academic employment. J Dent Educ 2016;80:1196-1204.

22. Gadbury-Amyot CC, Pyle MA, Van Ness CJ, Overman PR, West KP. Which way to lean? A national study of women dental faculty members' career aspirations and choices. J Dent Educ 2016;80:1392-1404.

23. Jena AB, Olenski AR, Blumenthal DM. Sex differences in physician salary in US public medical schools. JAMA Intern Med 2016;176:1294.

24. Ioannidou E, D'Souza RN, Macdougall MJ. Gender equity in dental academics: Gains and unmet challenges. J Dent Res 2014;93:5-7.

25. Kaatz A, Lee Y-G, Potvien A, et al. Analysis of National Institutes of Health R01 application critiques, impact, and criteria scores. Acad Med 2016;91:1080-1088.

26. Holliday E, Griffith KA, De Castro R, Stewart A, Ubel P, Jagsi R. Gender differences in resources and negotiation among highly motivated physician-scientists. J Gen Intern Med 2015;30:401-407.

27. DeCastro R, Griffith KA, Ubel PA, Stewart A, Jagsi R. Mentoring and the career satisfaction of male and female academic medical faculty. Acad Med 2014;89:301-311.

28. Ly DP, Jena AB. Sex differences in time spent on household activities and care of children among US physicians, 2003-2016. Mayo Clin Proc 2018;93:1484-1487.

29. Smith MK, Dundes L, Sinkford J, Thompson A, Oliver J. The implications of gender stereotypes for the dentistpatient relationship. J Dent Educ 2008;72:562-570.

30. Haden NK, Hendricson W, Ranney RR, et al. The quality of dental faculty work-life: Report on the 2007 dental school faculty work environment survey. J Dent Educ 2008;72:514-531.

31. Nasseh K, Vujicic M. The relationship between education debt and career choices in professional programs. J Am Dent Assoc 2017;148:825-833.

32. Freund KM, Raj A, Kaplan SE, et al. Inequities in academic compensation by gender. Acad Med 2016;91:1068-1073.

33. Sukhera J, Watling C. A framework for integrating implicit bias recognition into health professions education. Acad Med 2018;93:35-40.

Address correspondence to: Lisa Simon, DMD

Harvard School of Dental Medicine

188 Longwood Avenue Boston, MA 02115

E-mail: lisa_simon@hms.harvard.edu 